This is a self-archived version of an original article. This version may differ from the original in pagination and typographic details.

Author(s): Holmstedt, Suvi; George, Lijo; Koivuporras, Alisa; Valkonen, Arto; Candeias, Nuno

Title: Deoxygenative Divergent Synthesis : En Route to Quinic Acid Chirons

Year: 2020

Version: Accepted version (Final draft)

Copyright: @ 2020 American Chemical Society

Rights: In Copyright

Rights url: http://rightsstatements.org/page/lnC/1.0/?language=en

Please cite the original version:

Holmstedt, S., George, L., Koivuporras, A., Valkonen, A., \& Candeias, N. R. (2020). Deoxygenative Divergent Synthesis : En Route to Quinic Acid Chirons. Organic Letters, 22(21), 8370-8375.

https://doi.org/10.1021/acs.orglett.0c02995 


\title{
Deoxygenative divergent synthesis: en route to quinic acid chirons
}

\author{
Suvi Holmstedt, ${ }^{*[\mathrm{a}]}$ Lijo George, ${ }^{[\mathrm{a}]}$ Alisa Koivuporras, ${ }^{[\mathrm{a}]}$ Arto Valkonen, ${ }^{[\mathrm{b}]}$ Nuno R. Candeias*[a],[c] \\ ${ }^{[a]}$ S. Holmstedt, Dr. L. George, A. Koivuporras and Dr. N. R. Candeias, Faculty of Engineering and Natural Sciences, \\ Tampere University, Korkeakoulunkatu 8, 33101 Tampere, Finland, Email: suvi.holmstedt @ tuni.fi \\ ${ }^{[b]}$ Dr. A. Valkonen, Department of Chemistry, University of Jyväskylä, P.O. Box 35, 40014 Jyväskylä, Finland \\ ${ }^{[c]}$ Dr. N. R. Candeias, LAQV-REQUIMTE, Department of Chemistry, University of Aveiro, 3810-193 Aveiro, Portugal, \\ Email: ncandeias@ua.pt
}

Supporting Information Placeholder
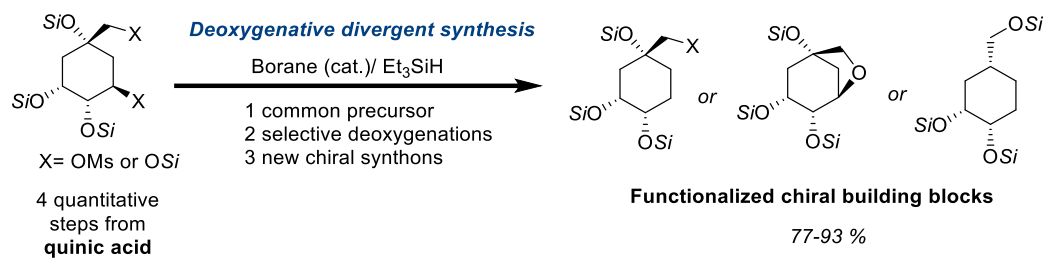

\begin{abstract}
The installation of vicinal mesylate and silyl ether groups in a quinic acid derivative, generates a system prone for stereoselective borane-catalyzed hydrosilylation through a siloxonium intermediate. The diversification of the reaction conditions allowed the construction of different defunctionalized fragments foreseen as useful synthetic fragments. The selectivity of the hydrosilylation was rationalized based on deuteration experiments and computational studies.
\end{abstract}

Synthetic strategies remain critically dependent on hemisynthesis or chiral pool despite the plethora of currently available catalytic asymmetric transformations. ${ }^{1}$ The contemporary mandatory transition from fossil to bio-based carbon resources calls for the development of synthetic transformations that maximize the full potential of chemical entities or fragments created by Nature. Saccharides are the main components of biomass and the efforts done for their integration in biorefineries have augmented the development of methods for removal of their oxygen functionalities. ${ }^{2}$ Dehydration $^{3}$ and selective cleavage of $\mathrm{C}-\mathrm{O}$ bonds ${ }^{4}$ of saccharides have been explored in the expansion of the biomass-derived chemical space..$^{5}$ The Yamamoto's seminal $\mathrm{B}\left(\mathrm{C}_{6} \mathrm{~F}_{5}\right)_{3}$-catalyzed hydrosilylation of $\mathrm{C}-\mathrm{O}$ bonds ${ }^{6}$ has been used in the extensive deoxygenation of saccharides ${ }^{7}$ and recently in the regioselective deoxygenation of saccharides, ${ }^{8}$ and polyols ${ }^{8 c}$ to provide new chiral entities (Scheme 1a). Alternative boron catalysts such as Piers' borane $\left(\mathrm{HB}\left(\mathrm{C}_{6} \mathrm{~F}_{5}\right)_{2}\right)^{9}$ and more recently $\left.\mathrm{B}\left(3,5-\mathrm{CF}_{3}\right)_{2} \mathrm{C}_{6} \mathrm{H}_{3}\right)_{3},{ }^{10}$ have been demonstrated to catalyze the silylative deoxygenation of biomass-derived sugars. ${ }^{11}$ The outcome of this deoxygenation method depends on several stereochemical and electronic parameters: first and foremost is the structure of the oxygenated substrate, ${ }^{8 \mathrm{a}}$ as vicinal groups can assist the $\mathrm{C}-\mathrm{O}$ bond cleavage. ${ }^{8 c}$ The second parameter is the hydrosilane employed, ${ }^{8 \mathrm{~b}, 8 \mathrm{c}}$ and the third is the fluoroarylborane catalyst. ${ }^{12}$ Gagné and co-workers have recently progressed the field by replacing hydrosilanes by hydroboranes as precursors of $\mathrm{H}$ -
$\mathrm{B}\left(\mathrm{C}_{6} \mathrm{~F}_{5}\right)_{3}{ }^{-}$hydride in the $\mathrm{C}-\mathrm{O}$ bond cleavage with different selectivities than the ones observed in the hydrosilylation. ${ }^{13}$

Morandi $^{14}$ and Oestreich ${ }^{15}$ have expanded the $\mathrm{B}\left(\mathrm{C}_{6} \mathrm{~F}_{5}\right)_{3^{-}}$ catalyzed hydrosilylation of $\mathrm{C}\left(s p^{3}\right)-\mathrm{O}$ bonds to 1,2-diols and primary tosylates, respectively. Both methods are effective in cleaving the terminal $\mathrm{C}-\mathrm{O}$ bond, the former due to the formation of a cyclic siloxane intermediate and the latter due to the higher reactivity of the tosylate compared with the silyl ether. Although suitable for the cleavage of primary tosylates containing a primary silyl ether (Scheme $1 \mathrm{~b}, \mathrm{R}=\mathrm{TBDMS}, \mathrm{n}=3$ 5 ), or an aryl ether (Scheme $1 \mathrm{~b}, \mathrm{R}=\mathrm{Ar}, \mathrm{n}=1$ or 5 ), rearranged products from anchimeric assistance were observed for 1,2diols (Scheme 1b, bottom). Indeed, the non-selective opening of a three-membered silyloxonium ion leads to the indiscriminate formation of a primary and secondary silyl ether. Substituents' migration competing with direct deoxygenation processes was further explored by Morandi, providing a reductive pinacol-type rearrangement of vicinal diols. ${ }^{16}$ On a related note, the $\mathrm{B}\left(\mathrm{C}_{6} \mathrm{~F}_{5}\right)_{3}$-catalyzed hydrosilylation of tetrasubstituted epoxides leads to a migratory ring-opening process after the formation of a silyloxonium ion intermediate. ${ }^{17}$ While the $\mathrm{B}\left(\mathrm{C}_{6} \mathrm{~F}_{5}\right)_{3}$-catalyzed hydrosilylation of $\mathrm{C}-\mathrm{O}$ bonds has been rapidly expanding the accessibility to saccharides-derived chiral fragments for synthesis, ${ }^{8 c, 10-11,13,18}$ we envisioned that different chiral synthons ${ }^{19}$ could be reached by focusing on natural cyclitols.

Quinic acid 1 was provisionally considered as one suitable feedstock for the bio-based benzoic acid production ${ }^{20}$ or other aromatics. ${ }^{21}$ However, high cost associated with the use of 
glucose as feedstock for bacterial production of quinic acid ${ }^{22}$ has again relegated this cyclitol to the chiral pool. ${ }^{23}$ Nevertheless, quinic acid and its acyl-derivatives are widespread secondary metabolites of the shikimic acid pathway ${ }^{24}$ in plants and can be obtained for instance from coffee beans, plants, fruits and even food wastes. ${ }^{25}$ Herein we present our efforts towards the selective cleavage of $\mathrm{C}\left(s p^{3}\right)-\mathrm{O}$ bonds of a common quinic acid-derived precursor with judiciously selected $O$-substituents, into diverse chiral fragments (Scheme 1c).

Scheme 1. $B\left(C_{6} F_{5}\right)_{3}$-catalyzed selective deoxygenation of 1,2diols and primary alkyl tosylates.

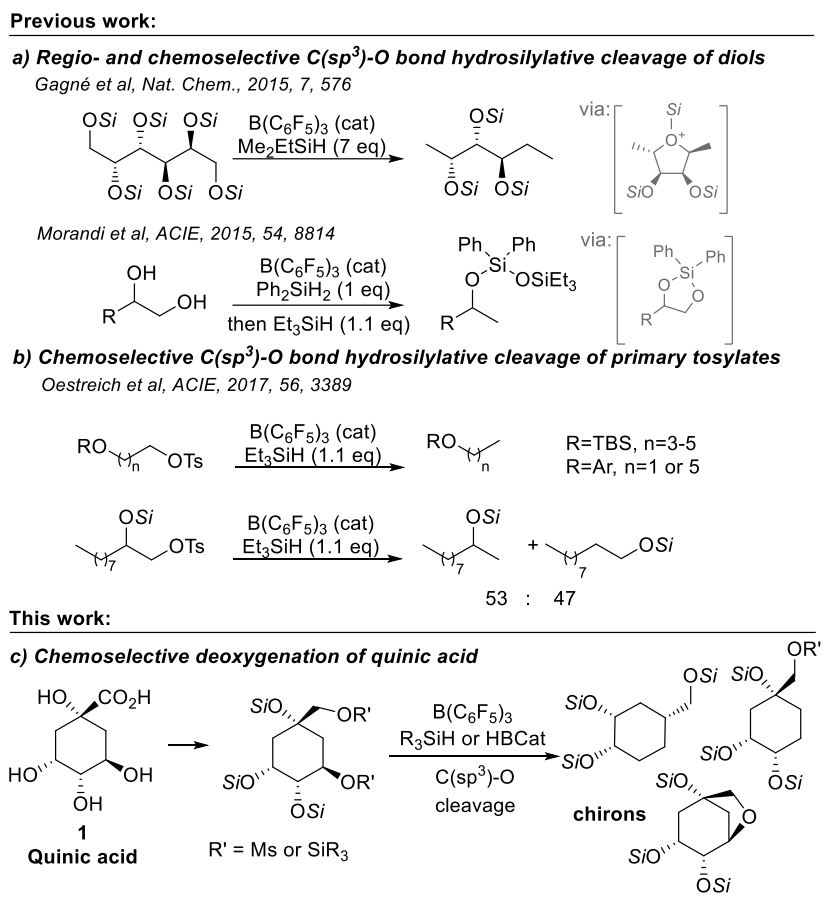

Aware of putative effects imposed by the diverse conformations of cyclitols on the regioselectivity of deoxygenation using the $\mathrm{B}\left(\mathrm{C}_{6} \mathrm{~F}_{5}\right)_{3} / \mathrm{SiH}$ system, the vicinal cis diol moiety of quinide $\mathbf{2}$ was derivatized to several functional groups. Besides conferring the desired conformational effect, further deprotection after deoxygenation would provide substrates prone to typical $\mathrm{C}-\mathrm{C}$ oxidative cleavage and subsequently give chiral linear $\mathrm{C}_{7}$ fragments. Attempts on the hydrosilylation of cyclitol derivatives 3-13 (Scheme 2) failed in providing any deoxygenated products (see supporting information section 1 for complete rationale).

Scheme 2. Quinic acid derivatives explored in $B\left(C_{6} F_{5}\right)_{3}-$ catalyzed hydrosilylation
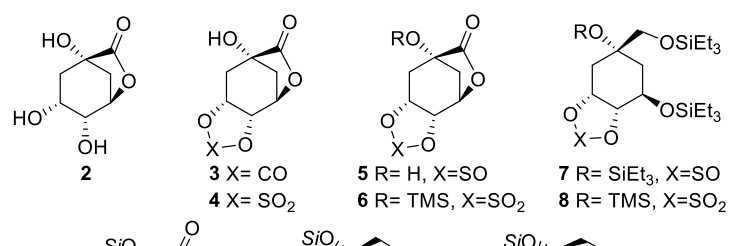

$7 \mathrm{R}=\mathrm{SiEt}_{3}, \mathrm{X}=\mathrm{SO}$

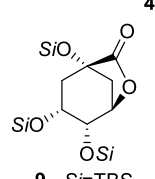

$4 \mathrm{X}=\mathrm{SO}_{2}$

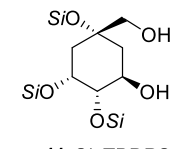

SiO"

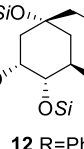

10 Si=TBDPS

$8 \mathrm{R}=\mathrm{TMS}, \mathrm{X}=\mathrm{SO}_{2}$
The discouraging lack of reactivity of the silylated quinic acid derivatives prompted us to explore the anchimeric assistance by silyl ethers in the $\mathrm{C}-\mathrm{O}$ bond cleavage of tosylates, as previously reported by Oestreich and co-workers. ${ }^{15}$ Excellent chemoselectivity was reported for the deoxygenation of primary alkyl tosylates from non-vicinal diol derivatives. However, the formation of a three-membered silyloxonium ion intermediate resulted in rearranged products and lack of regioselectivity was observed when considering aliphatic 1,2vicinal diol systems. Gratifyingly, treatment of $\mathbf{1 5}$ with different catalyst loadings and amounts of triethylsilane resulted in formation of $\mathbf{1 6}$ and/or $\mathbf{1 7}$ in different ratios (Scheme 3 and Table S1 in SI for further experiments). Silyl ethers derived from primary and secondary alcohols have been reported to be more reactive towards $\mathrm{B}\left(\mathrm{C}_{6} \mathrm{~F}_{5}\right)_{3}$-catalyzed reduction with hydrosilanes than the ones derived from tertiary homologs. ${ }^{6 c, 6 \mathrm{~d}}$ On the other hand, the neighboring group assistance can deeply impact the regioselectivity. Notably, cleavage of the primary mesylate in $\mathbf{1 5}$ was accompanied by stereospecific migration of the silyloxy group from the vicinal tertiary carbon to provide $\mathbf{1 7}$ (Scheme 3). The absolute configuration of the deoxygenated product was determined through $\mathrm{x}$-ray diffraction analysis of the 3,5-dinitrobenzoyl derivative 18, obtained after desilylation of $\mathbf{1 7}$ and benzoylation of the triol 17'.

Scheme 3. Deoxygenation of quinic acid derivative 15

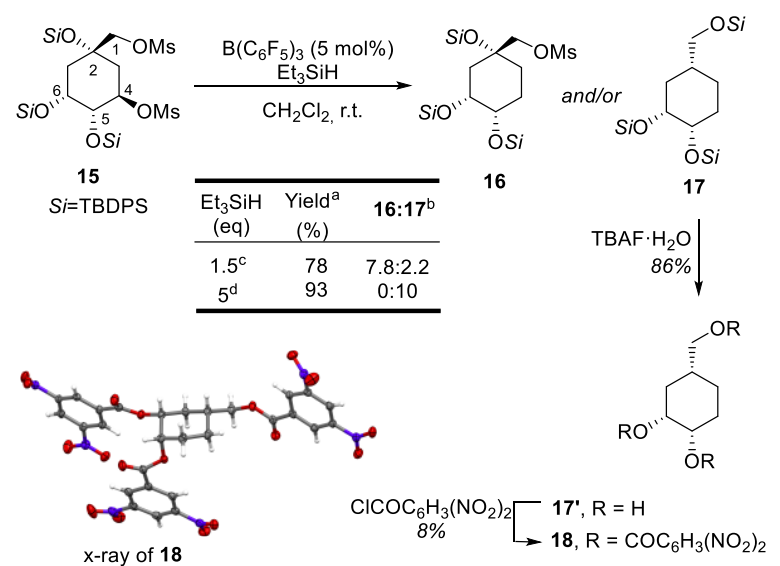

[a] $15(0.14 \mathrm{mmol})$ and $\mathrm{B}\left(\mathrm{C}_{6} \mathrm{~F}_{5}\right)_{3}$ in $\mathrm{CH}_{2} \mathrm{Cl}_{2}$, at r.t. followed by addition of $\mathrm{Et}_{3} \mathrm{SiH} ;{ }^{[b]}$ ratio determined from isolated yields; ${ }^{[\mathrm{c}]}[\mathbf{1 5}]$ $=0.05 \mathrm{M} ;{ }^{[\mathrm{d}]}[\mathbf{1 5}]=0.3 \mathrm{M}$

Attempts to overcome the higher propensity of $\mathrm{C} 4$ towards deoxygenation, by replacing the mesylate with protecting groups proved futile. Instead, $\mathrm{B}\left(\mathrm{C}_{6} \mathrm{~F}_{5}\right)_{3} / \mathrm{SiH}$ treatment of $\mathbf{2 0}$ having the secondary hydroxyl protected as silyl ether (20b) resulted in the fast intramolecular cyclization to bicyclic compound 21 in up to $88 \%$ yield (Scheme 4). Exposure of MOM-ether 20c to the same conditions resulted in the formation of compound $\mathbf{2 0 d}$ in $78 \%$ yield (Scheme 5). Treatment of methyl ether $\mathbf{2 0 d}$ with additional triethylsilane (1.1 equivalents) in presence of $\mathrm{B}\left(\mathrm{C}_{6} \mathrm{~F}_{5}\right)_{3}$ led to formation of cyclic ether 21, as deduced from crude NMR. Carbamoyl protected 20e was unreactive towards $\mathrm{B}\left(\mathrm{C}_{6} \mathrm{~F}_{5}\right)_{3}$-catalyzed hydrosilylation, and only starting material was recovered, despite the harsh reaction conditions used (20 mol\% catalyst, excess of silane and refluxing toluene). The structural complexity of compound $\mathbf{2 1}^{26}$ was broken down through oxidative cleavage of the $\mathrm{C}-\mathrm{C}$ bond upon desilylation and oxidation of the cis glycol moiety via Malaprade oxidation to 
Scheme 4. Formation and controlled cleavage of bicyclic tetrahydrofuran 21

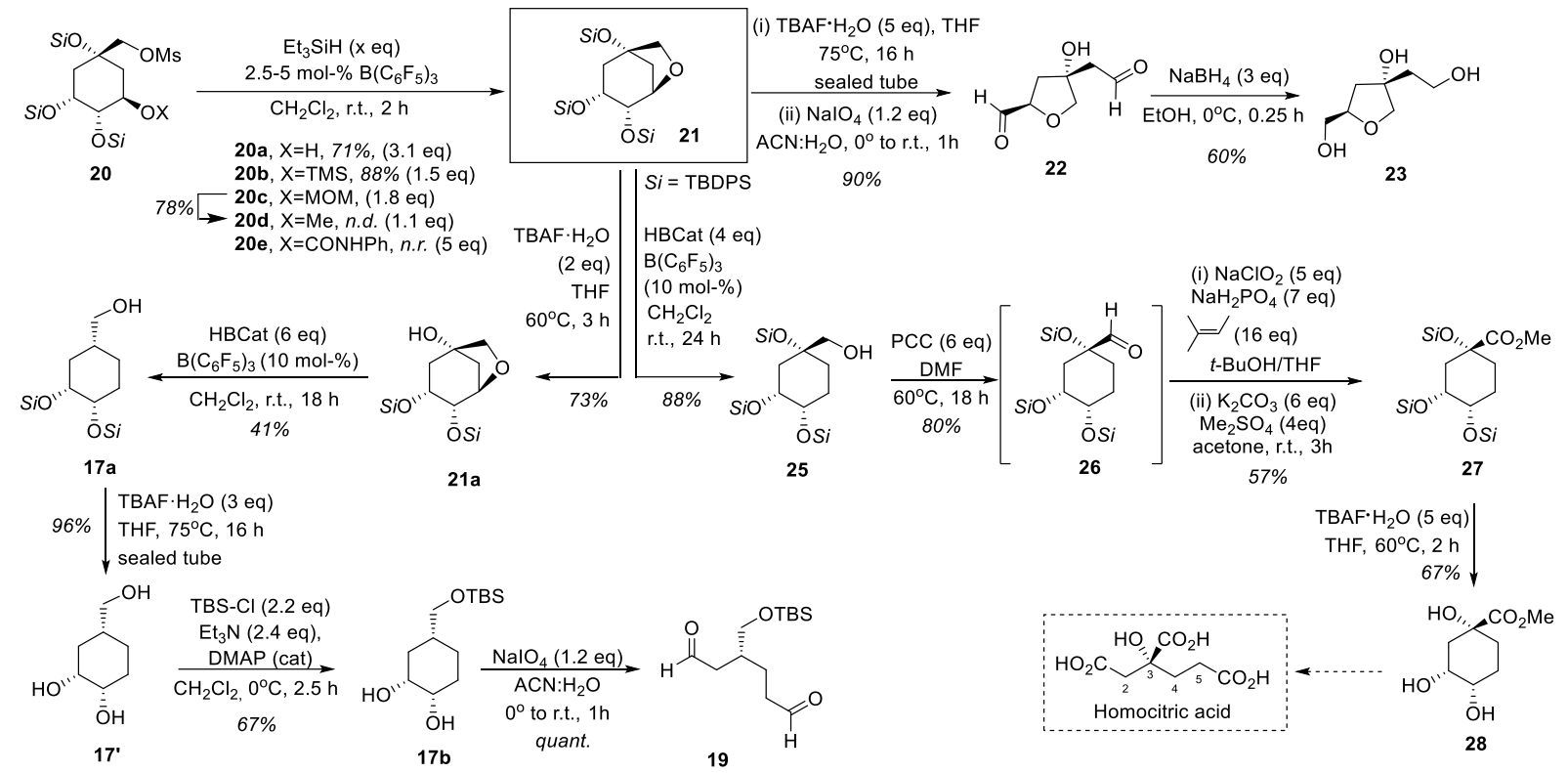

(n.d = yield not deternined; n.r. $=$ no reaction $)$

provide dialdehyde $\mathbf{2 2}$ in excellent yield. The cyclic ethers 22 and 23, are envisioned as interesting synthetic intermediates due to the presence of oxygen functionality-containing substituents at $\mathrm{C} 1$ and $\mathrm{C} 3$ positions of the tetrahydrofuran core. ${ }^{27}$ The selective deprotection of the tertiary silyl ether of $\mathbf{2 1}$ followed by similar cleavage with catechol borane and desilylation also provided compound 17a. A sequence of silyl ethers' cleavage and primary alcohol protection resulted in $\mathbf{1 7 b}$ that was submitted to Malaprade oxidation providing dialdehyde 19, envisioned as a rich fragment for stereoselective synthesis due to the three functionalities and structural similarities with Perlin aldehydes. ${ }^{28}$ Impelled by the bicyclic skeleton of 21, the controlled modification of its stereogenic carbons was attempted. The lack of reactivity of $\mathbf{2 1}$ towards cleavage of the $\mathrm{O}-\mathrm{Si}$ bond by $\mathrm{B}\left(\mathrm{C}_{6} \mathrm{~F}_{5}\right)_{3}$-catalyzed hydrosilylation was overcome by reduction with catechol borane, as recently developed by Gagne, ${ }^{13}$ resulting in the selective cleavage of the $\mathrm{C}-\mathrm{O}$ bond from the secondary carbon to provide 25 in $87 \%$ yield.

Selective oxidation of primary alcohol moiety of $\mathbf{2 5}$ followed by one-pot esterification and desilylation led to $\mathbf{2 8}$, a known intermediate in the synthesis of homocitric acid. ${ }^{29}$ Even though not attempted, it is worth noticing that the use of deuteriocatecholborane in the manipulation of $\mathbf{2 1}$ would provide an entry for the preparation of labeled homocitrate. Although of potential interest for biological studies, deuterium labeling at position 5 remains unveiled. ${ }^{29 a}, 30$.

The observed preferred chemoselectivity for $\mathrm{C}-\mathrm{O}$ bond cleavage of the secondary carbon over the primary mesylate in 15, suggests the formation of the three-membered silyloxonium ion as proposed previously by Oestreich. The higher propensity of $\mathrm{C} 4$ for deoxygenation compared to $\mathrm{C} 1$ is justified by the easier formation of the strained three-membered silyloxonium ion in C4-C5 than in C1-C2, as the later will turn C2 into a spiro carbon. Such event should become less energy demanding after removal of one of the carbocycle substituents. Additionally, the easier access of the hydride to $\mathrm{C} 4$ over $\mathrm{C} 5$ renders this process highly regioselective in the opening of the siloxonium. Motivated by the excellent regioselectivity in opening of the putative three-membered silyloxonium ion with hydrosilanes, compound 29, an analog of $\mathbf{1 5}$, was submitted to similar deoxygenation protocol. The treatment of cyclohexanol derivative 29 with $\mathrm{B}\left(\mathrm{C}_{6} \mathrm{~F}_{5}\right)_{3}$ and silyl hydrides resulted in cleavage of the $\mathrm{C}-\mathrm{O}$ bond and migration of the silyl ether moiety to the primary carbon (Scheme 5), contrasting with the previously reported lack of selectivity for deoxygenation of primary tosylates vicinal to a secondary silyl ether. ${ }^{15}$ While no alkyl migration was observed in the deoxygenations of quinic acid derivatives, which was expected given the precedents on the hydrosilylation of epoxides in acyclic systems ${ }^{17}$ the migration of hydride from the primary to tertiary carbon was considered. ${ }^{31}$ When using $\mathrm{Et}_{3} \mathrm{SiD}$ as a reducing agent, the deuteration occurred selectively at the primary carbon, affording $d-\mathbf{3 0}$ in $57 \%$ after isolation. Similar behavior was observed in the hydrosilylation of $\mathbf{1 5}$ with $\mathrm{Et}_{3} \mathrm{SiD}$. The delivery of the deuteride to the opposite face of the silyl ethers of the cyclohexane derivative (absolute configuration determined from inspection of vicinal coupling constants) seems to indicate a different mechanism when comparing with the tertiary silyl ether/primary mesylate counterpart.

Scheme 5. $B\left(C_{6} F_{5}\right)_{3}$-catalyzed siloxonium opening with Et $_{3}$ SiD.
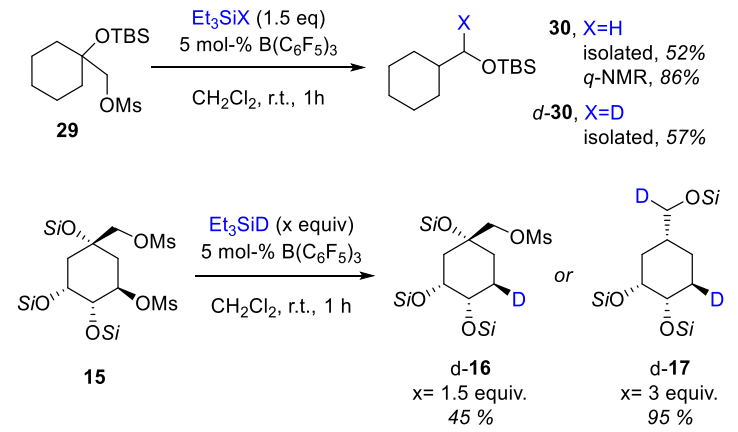
Scheme 6. Free energy profile (M06-2X/6-311++G**//M06-2X/6-31G**) and mechanistic representation for deoxygenation of model substrate $\mathrm{sm}$, via siloxonium and 1,2-hydride shift. Values are presented in $\mathrm{kcal} / \mathrm{mol}$, referring to the initial pair of $\mathrm{sm}$ and $\mathrm{Et}_{3} \mathrm{Si}-\mathrm{H}-\mathrm{B}\left(\mathrm{C}_{6} \mathbf{F}_{5}\right)_{3}$

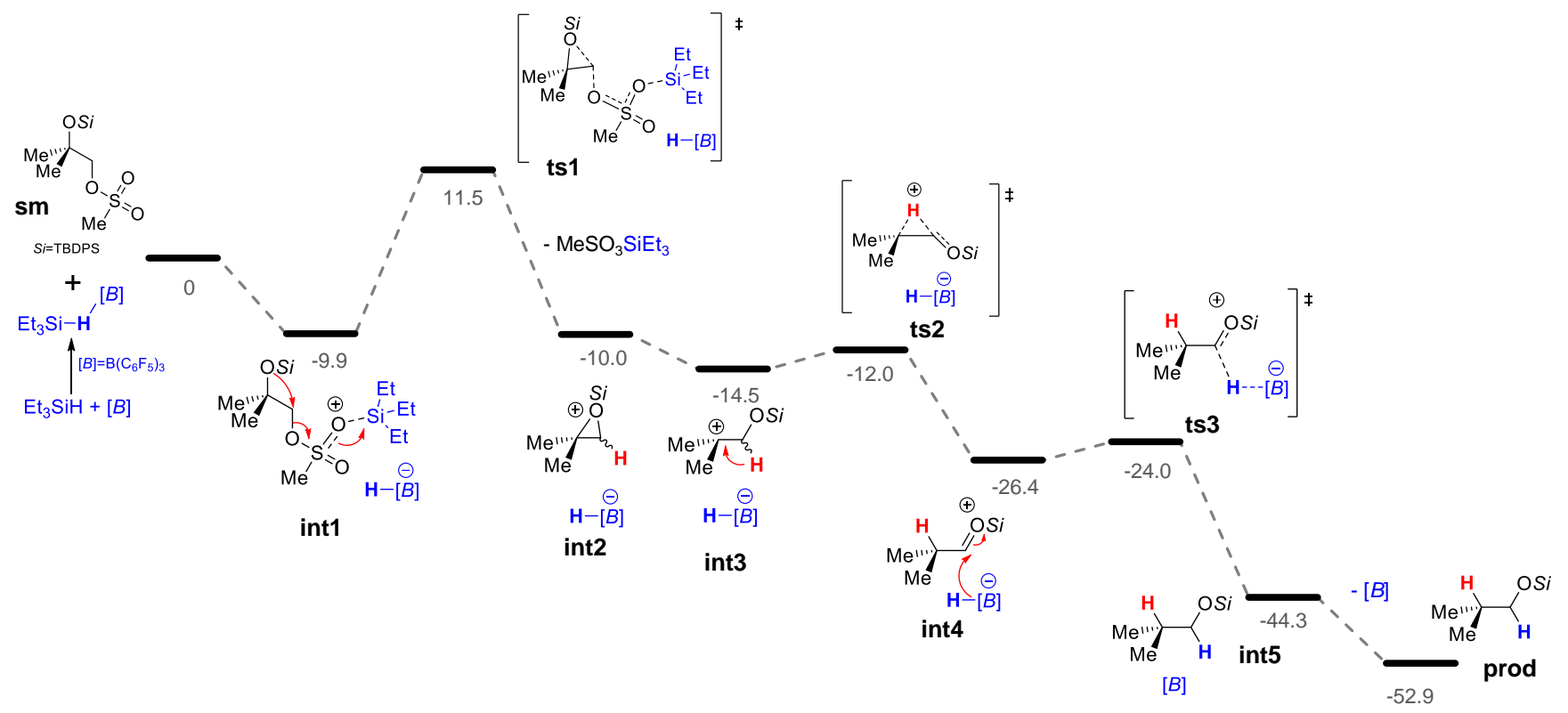

In order to get further insight on the formation of the silyloxonium intermediate and its regioselective opening, a simplified system was studied by means of Density Functional Theory $^{32}$ (Scheme 6), and geometries of the transition states calculated (please consult Figure S1 and full computational account in SI). The energetically favorable interaction of the mesylate group of sm with silylium ion in int1 increases the electrophilic character of the primary carbon, triggering the formation of the silyloxonium ion int 2 through a $21.4 \mathrm{kcal} / \mathrm{mol}$ energy barrier. $\mathrm{C}-\mathrm{O}$ bond lengths in the siloxonium int 2 differ by $0.05 \AA$, with the most substituted bond being elongated. The equilibration of the siloxonium to int3, where the abovementioned $\mathrm{C}-\mathrm{O}$ bond is clearly broken $\left(\mathrm{d}_{\mathrm{C}-\mathrm{O}}=2.385 \AA\right)$, is energetically more favorable by $4.5 \mathrm{kcal} / \mathrm{mol}$. The 1,2 -hydride shift for neutralization of the positive charge on the tertiary carbon is a favorable process with int4 being $11.9 \mathrm{kcal} / \mathrm{mol}$ more stable than int3. Additionally, the energy barrier for the 1,2 -hydride migration through ts 2 is only $2.5 \mathrm{kcal} / \mathrm{mol}$. The hydride delivery from the hydridoborate anion to the electrophilic carbon of the oxocarbenium is almost spontaneous and int 4 can simply overcome the barely existent energy barrier of $2.4 \mathrm{kcal} / \mathrm{mol}$ for ts 3 to ultimately form the very stable silyl ether int5. The overall process is energetically favored as demonstrated by the $\Delta \mathrm{G}_{\mathrm{f}}$ of $\operatorname{prod}(52.9 \mathrm{kcal} / \mathrm{mol})$ with the rate limiting step being the formation of the siloxonium int2.

In conclusion, we have described the $\mathrm{B}\left(\mathrm{C}_{6} \mathrm{~F}_{5}\right)_{3}$-catalyzed defunctionalization of a cyclitol through hydride delivery to three-membered silyloxonium ions. The success of the deoxygenation of quinide and derivatives using this hydrosilylation depends on the protecting groups. Nevertheless, the achieved deoxygenations proved highly stereoselective and allowed the diversification of chiral fragments that can be obtained from quinic acid. The expansion of this transitionmetal free deoxygenation protocol to cyclitols had diversified the array of molecules and fragments that can be obtained from biorenewables.

\section{ASSOCIATED CONTENT}

\section{Supporting Information}

The Supporting Information is available free of charge on the ACS Publications website.

Experimental details, preliminary studies on hydrosilylation and characterization data of all synthetic intermediates, full accounts on computational calculations and ${ }^{1} \mathrm{H}$ and ${ }^{13} \mathrm{C}$ NMR copies of spectra for all reported compounds. (PDF)

X-ray structure of $\mathbf{1 8}(\mathrm{CIF})$

\section{AUTHOR INFORMATION}

\section{Corresponding Authors}

*Suvi Holmstedt - Faculty of Engineering and Natural Sciences, Tampere University, Korkeakoulunkatu 8, 33101 Tampere, Finland;

orcid.org/0000-0003-0479-3629; Email: suvi.holmstedt@tuni.fi

*Nuno R. Candeias - Faculty of Engineering and Natural Sciences, Tampere University, Korkeakoulunkatu 8, 33101 Tampere, Finland and LAQV-REQUIMTE, Department of Chemistry, University of Aveiro, 3810-193 Aveiro, Portugal; orcid.org/0000-0003-2414-9064; Email: ncandeias@ua.pt

\section{Authors}

Lijo George - Faculty of Engineering and Natural Sciences, Tampere University, Korkeakoulunkatu 8, 33101 Tampere, Finland

Alisa Koivuporras - Faculty of Engineering and Natural Sciences, Tampere University, Korkeakoulunkatu 8, 33101 Tampere, Finland

Arto Valkonen - Department of Chemistry, University of Jyväskylä, P.O. Box 35, 40014, Jyväskylä, Finland

\section{Author Contributions}

The manuscript was written through contributions of all authors.

\section{ACKNOWLEDGMENT}


The Academy of Finland is duly acknowledged for financial support to N. R. C. (Decisions No. 326487 and 326486) and to A. V. (No. 314343). Finnish Cultural Foundation is acknowledged for financial support to S. H. (00190336). CSC-IT Center for Science Ltd, Finland is acknowledged for the allocation of computational resources. Professor Luis F. Veiros (Centro de Química Estrutural, Instituto Superior Técnico, Universidade de Lisboa, Portugal) is acknowledged for fruitful discussions on the computational section.

\section{REFERENCES}

(1) (a) Brill, Z. G.; Condakes, M. L.; Ting, C. P.; Maimone, T. J. Navigating the Chiral Pool in the Total Synthesis of Complex Terpene Natural Products. Chem. Rev. 2017, 117, 11753-11795; (b) Pfaffenbach, M.; Bakanas, I.; O'Connor, N. R.; Herrick, J. L.; Sarpong, R. Total Syntheses of Xiamycins A, C, F, H and Oridamycin A and Preliminary Evaluation of their Anti-Fungal Properties. Angew. Chem. Int. Ed. Engl. 2019; (c) Hu, N.; Dong, C.; Zhang, C.; Liang, G. Total Synthesis of (-)-Indoxamycins A and B. Angew. Chem. Int. Ed. Engl. 2019, 58, 6659-6662; (d) Hung, K.; Condakes, M. L.; Novaes, L. F. T.; Harwood, S. J.; Morikawa, T.; Yang, Z.; Maimone, T. J. Development of a Terpene Feedstock-Based Oxidative Synthetic Approach to the Illicium Sesquiterpenes. J. Am. Chem. Soc. 2019, 141, 3083-3099.

(2) (a) Sheldon, R. A. The Road to Biorenewables: Carbohydrates to Commodity Chemicals. ACS Sustain. Chem. Eng. 2018, 6, 4464-4480; (b) Mika, L. T.; Csefalvay, E.; Nemeth, A. Catalytic Conversion of Carbohydrates to Initial Platform Chemicals: Chemistry and Sustainability. Chem. Rev. 2018, 118, 505-613.

(3) (a) Zhang, X.; Wilson, K.; Lee, A. F. Heterogeneously Catalyzed Hydrothermal Processing of $\mathrm{C}_{5}-\mathrm{C}_{6}$ Sugars. Chem. Rev. 2016, 116, 12328-12368; (b) Gómez Millán, G.; Hellsten, S.; Llorca, J.; Luque, R.; Sixta, H.; Balu, A. M. Recent Advances in the Catalytic Production of Platform Chemicals from Holocellulosic Biomass. ChemCatChem 2019, 11, 2022-2042.

(4) Kühne, B.; Vogel, H.; Meusinger, R.; Kunz, S.; Kunz, M. Mechanistic study on $-\mathrm{C}-\mathrm{O}-$ and $-\mathrm{C}-\mathrm{C}-$ hydrogenolysis over $\mathrm{Cu}$ catalysts: identification of reaction pathways and key intermediates. Catal. Sci. Technol. 2018, 8, 755-767.

(5) (a) Brun, N.; Hesemann, P.; Esposito, D. Expanding the biomass derived chemical space. Chem. Sci. 2017, 8, 4724-4738; (b) Bender, T. A.; Dabrowski, J. A.; Gagné, M. R. Homogeneous Catalysis for the Production of Low-volume, High-value Chemicals from Biomass. Nat. Rev. Chem. 2018, 2, 35-46.

(6) (a) Yamamoto, Y.; Bajracharya, G. B.; Nogami, T.; Jin, T.; Matsuda, K.; Gevorgyan, V. Reduction of Carbonyl Function to a Methyl Group. Synthesis 2004, 308-311; (b) Gevorgyan, V.; Liu, J.-X.; Rubin, M.; Benson, S.; Yamamoto, Y. A novel reduction of alcohols and ethers with a $\mathrm{HSiEt}_{3}$ catalytic $\mathrm{B}\left(\mathrm{C}_{6} \mathrm{~F}_{5}\right)_{3}$ system. Tetrahedron Lett. 1999, 40, 8919-8922; (c) Gevorgyan, V. V.; Rubin, M.; Benson, S.; Liu, J. X.; Yamamoto, Y. A novel $\mathrm{B}\left(\mathrm{C}_{6} \mathrm{~F}_{5}\right)_{3}$-catalyzed reduction of alcohols and cleavage of aryl and alkyl ethers with hydrosilanes. J. Org. Chem. 2000, 65, 6179-6186; (d) Gevorgyan, V.; Rubin, M.; Liu, J.-X.; Yamamoto, Y. A Direct Reduction of Aliphatic Aldehyde, Acyl Chloride, Ester, and Carboxylic Functions into a Methyl Group. J. Org. Chem. 2001, 66, 1672-1675.

(7) Adduci, L. L.; McLaughlin, M. P.; Bender, T. A.; Becker, J. J.; Gagné, M. R. Metal-Free Deoxygenation of Carbohydrates. Angew. Chem. Int. Edit. 2014, 53, 1646-1649.

(8) (a) Seo, Y.; Gagné, M. R. Positional Selectivity in the Hydrosilylative Partial Deoxygenation of Disaccharides by Boron Catalysts. ACS Catal. 2017, 8, 81-85; (b) Hein, N. M.; Seo, Y.; Lee, S. J.; Gagné, M. R. Harnessing the reactivity of poly(methylhydrosiloxane) for the reduction and cyclization of biomass to high-value products. Green Chem. 2019, 21, 2662-2669; (c) Adduci, L. L.; Bender, T. A.; Dabrowski, J. A.; Gagné, M. R. Chemoselective Conversion of Biologically Sourced Polyols into Chiral Synthons. Nat. Chem. 2015, 7, 576-581.

(9) (a) Parks, D. J.; Piers, W. E.; Yap, G. P. A. Synthesis, Properties, and Hydroboration Activity of the Highly Electrophilic
Borane Bis(pentafluorophenyl)borane, $\mathrm{HB}\left(\mathrm{C}_{6} \mathrm{~F}_{5}\right)_{2}$. Organometallics 1998, 17, 5492-5503; (b) Parks, D. J.; von H. Spence, R. E.; Piers, W. E. Bis(pentafluorophenyl)borane: Synthesis, Properties, and Hydroboration Chemistry of a Highly Electrophilic Borane Reagent. Angew. Chem., Int. Ed. Engl. 1995, 34, 809-811; (c) Zhang, J.; Park, S.; Chang, S. Selective C-O Bond Cleavage of Sugars with Hydrosilanes Catalyzed by Piers' Borane Generated In Situ. Angew. Chem. Int. Ed. Engl. 2017, 56, 13757-13761.

(10) Seo, Y.; Lowe, J. M.; Gagné, M. R. Controlling Sugar Deoxygenation Products from Biomass by Choice of Fluoroarylborane Catalyst. ACS Catal. 2019, 9, 6648-6652.

(11) Seo, Y.; Gagné, M. R. Silylium $\left(\mathrm{R}_{3} \mathrm{Si}^{+}\right)$Catalyzed Condensative Cyclization for Anhydrosugar Synthesis. ACS Catal. 2018, 8, 6993-6999.

(12) Patrick, E. A.; Piers, W. E. Twenty-five years of bispentafluorophenyl borane: a versatile reagent for catalyst and materials synthesis. Chem. Commun. 2020, 56, 841-853.

(13) Lowe, J. M.; Seo, Y.; Gagné, M. R. Boron-Catalyzed SiteSelective Reduction of Carbohydrate Derivatives with Catecholborane. ACS Catal. 2018, 8, 8192-8198.

(14) Drosos, N.; Morandi, B. Boron-Catalyzed Regioselective Deoxygenation of Terminal 1,2-Diols to 2-Alkanols Enabled by the Strategic Formation of a Cyclic Siloxane Intermediate. Angew. Chem. Int. Ed. Engl. 2015, 54, 8814-8818.

(15) Chatterjee, I.; Porwal, D.; Oestreich, M. B $\left(\mathrm{C}_{6} \mathrm{~F}_{5}\right)_{3}$-Catalyzed Chemoselective Defunctionalization of Ether-Containing Primary Alkyl Tosylates with Hydrosilanes. Angew. Chem. Int. Ed. Engl. 2017, $56,3389-3391$.

(16) Drosos, N.; Cheng, G. J.; Ozkal, E.; Cacherat, B.; Thiel, W.; Morandi, B. Catalytic Reductive Pinacol-Type Rearrangement of Unactivated 1,2-Diols through a Concerted, Stereoinvertive Mechanism. Angew. Chem. Int. Ed. Engl. 2017, 56, 13377-13381.

(17) The regioselective silyloxonium opening was reported to occur when using Piers borane: Zhang, J.; Park, S.; Chang, S. Piers' Borane-Mediated Hydrosilylation of Epoxides and Cyclic Ethers. Chem. Commun. 2018, 54, 7243-7246.

(18) Bender, T. A.; Dabrowski, J. A.; Zhong, H.; Gagné, M. R. Diastereoselective $\mathrm{B}\left(\mathrm{C}_{6} \mathrm{~F}_{5}\right)_{3}$-Catalyzed Reductive Carbocyclization of Unsaturated Carbohydrates. Org. Lett. 2016, 18, 4120-4123.

(19) For selected examples on the use of chiral synthons, from carbohydrates: (a) Lin, S.; Guo, X.; Qin, K.; Feng, L.; Zhang, Y.; Tang, Y. Efficient Production of Biomass-Derived C4 Chiral Synthons in Aqueous Solution. ChemCatChem 2017, 9, 4179-4184; (b) Hollingsworth, R. I.; Wang, G. Toward a Carbohydrate-Based Chemistry: Progress in the Development of General-Purpose Chiral Synthons from Carbohydrates. Chem. Rev. 2000, 100, 4267-4282; (c) Ramesh, Namakkal G.; Balasubramanian, Kalpattu K. 2-C-Formyl Glycals: Emerging Chiral Synthons in Organic Synthesis. Eur. J. Org. Chem. 2003, 4477-4487; (d) Cairns, R.; Gomm, A.; Ryan, J.; Clarke, T.; Kulcinskaja, E.; Butler, K.; O'Reilly, E. Conversion of Aldoses to Valuable $\omega$-Amino Alcohols Using Amine Transaminase Biocatalysts. ACS Catal. 2018, 9, 1220-1223; from non-carbohydrates: (e) Hoffmann, R. W. meso Compounds: stepchildren or favored children of stereoselective synthesis? Angew. Chem. Int. Ed. Engl. 2003, 42, 1096-1109; (f) Guo, C.; Saifuddin, M.; Saravanan, T.; Sharifi, M.; Poelarends, G. J. Biocatalytic Asymmetric Michael Additions of Nitromethane to $\alpha, \beta$-Unsaturated Aldehydes via Enzyme-bound Iminium Ion Intermediates. ACS Catal. 2019, 9, 4369-4373; (g) Brenna, E.; Crotti, M.; Gatti, F. G.; Monti, D.; Parmeggiani, F.; Santangelo, S. Asymmetric Bioreduction of $\beta$-Acylaminonitroalkenes: Easy Access to Chiral Building Blocks with Two Vicinal NitrogenContaining Functional Groups. ChemCatChem 2017, 9, 2480-2487; (h) Chen, Y. H.; McDonald, F. E. New chiral synthons for efficient introduction of bispropionates via stereospecific oxonia-cope rearrangements. J. Am. Chem. Soc. 2006, 128, 4568-4569; (i) Hudlicky, T.; Thorpe, A. J. Current status and future perspectives of cyclohexadiene-cis-diols in organic synthesis: versatile intermediates in the concise design of natural products. Chem. Commun. 1996, 19932000; (j) Padarti, A.; Han, H. Rationally Designed Chiral Synthons Enabling Asymmetric Z- and E-Selective Vinylogous Aldol Reactions of Aldehydes. Org. Lett. 2018, 20, 1448-1452. 
(20)

Arceo, E.; Ellman, J. A.; Bergman, R. G. A direct, biomassbased synthesis of benzoic acid: formic acid-mediated deoxygenation of the glucose-derived materials quinic acid and shikimic acid. ChemSusChem 2010, 3, 811-813.

(21) (a) Assoah, B.; Veiros, L. F.; Afonso, C. A. M.; Candeias, N. R. Biomass-Based and Oxidant-Free Preparation of Hydroquinone from Quinic Acid. Eur. J. Org. Chem. 2016, 3856-3861; (b) Ran, N.; Knop, D. R.; Draths, K. M.; Frost, J. W. Benzene-Free Synthesis of Hydroquinone. J. Am. Chem. Soc. 2001, 123, 10927-10934.

(22) Pfennig, T.; Carraher, J. M.; Chemburkar, A.; Johnson, R. L.; Anderson, A. T.; Tessonnier, J.-P.; Neurock, M.; Shanks, B. H. A new selective route towards benzoic acid and derivatives from biomass-derived coumalic acid. Green Chem. 2017, 19, 4879-4888.

(23) (a) Enev, V. 2.11 Chiral Pool Synthesis: Chiral Pool Synthesis from Quinic Acid In Comprehensive Chirality; Carreira, E. M., Yamamoto, H., Eds.; Elsevier: Amsterdam, 2012, p 325-345; (b) Barco, A.; Benetti, S.; Risi, C. D.; Marchetti, P.; Pollini, G. P.; Zanirato, V. D-(-)-Quinic acid: a chiron store for natural product synthesis. Tetrahedron: Asymmetry 1997, 8, 3515-3545; (c) Mulzer, J.; Drescher, M.; Enev, V. S. Quinic Acid as Versatile Chiral Scaffold in Organic Synthesis. Curr. Org. Chem. 2008, 12, 1613-1630.

(24) Candeias, N. R.; Assoah, B.; Simeonov, S. P. Production and Synthetic Modifications of Shikimic Acid. Chem. Rev. 2018, 118, $10458-10550$

(25) (a) Wianowska, D.; Gil, M. Recent advances in extraction and analysis procedures of natural chlorogenic acids. Phytochem. Rev. 2018, 18, 273-302; (b) Clifford, M. N.; Jaganath, I. B.; Ludwig, I. A.; Crozier, A. Chlorogenic acids and the acyl-quinic acids: discovery, biosynthesis, bioavailability and bioactivity. Nat. Prod. Rep. 2017, 34, 1391-1421; (c) Yuda, N.; Tanaka, M.; Suzuki, M.; Asano, Y.; Ochi, H.; Iwatsuki, K. Polyphenols extracted from black tea (Camellia sinensis) residue by hot-compressed water and their inhibitory effect on pancreatic lipase in vitro. J. Food. Sci. 2012, 77, H254-261; (d) Grunovaitè, L.; Pukalskienė, M.; Pukalskas, A.; Venskutonis, P. R. Fractionation of black chokeberry pomace into functional ingredients using high pressure extraction methods and evaluation of their antioxidant capacity and chemical composition. J. Funct. Foods 2016, 24, 85-96; (e) Wang, J.; Lu, D.; Sun, Q.; Zhao, H.; Ling, X.; Ouyang, $\mathrm{P}$. Reactive extraction and recovery of mono-caffeoylquinic acids from tobacco wastes by trialkylphosphine oxide. Chem. Eng. Sci. 2012, 78, 53-62; (f) Santana-Méridas, O.; González-Coloma, A.; SánchezVioque, R. Agricultural residues as a source of bioactive natural products. Phytochem. Rev. 2012, 11, 447-466.
(26) For the synthesis of unprotected derivative see: Gorin, P. A. J. Replacement Reactions in the Quinic Acid Series. Can. J. Chem. 1963, 41, 2417-2423.

(27) (a) Benhamou, L.; Foster, R. W.; Ward, D. P.; Wheelhouse, K.; Sloan, L.; Tame, C. J.; Bučar, D.-K.; Lye, G. J.; Hailes, H. C.; Sheppard, T. D. Functionalised tetrahydrofuran fragments from carbohydrates or sugar beet pulp biomass. Green Chem. 2019, 21, 2035-2042; (b) Foster, R. W.; Tame, C. J.; Bucar, D. K.; Hailes, H. C.; Sheppard, T. D. Sustainable Synthesis of Chiral Tetrahydrofurans through the Selective Dehydration of Pentoses. Chem. Eur. J. 2015, 21, 15947-15950; (c) Monasterolo, C.; Muller-Bunz, H.; Gilheany, D. G. Very short highly enantioselective Grignard synthesis of 2,2disubstituted tetrahydrofurans and tetrahydropyrans. Chem. Sci. 2019, 10, 6531-6538.

(28) Reddy, L. V.; Kumar, V.; Sagar, R.; Shaw, A. K. Glycalderived D-hydroxy a,b-unsaturated aldehydes (Perlin aldehydes): versatile building blocks in organic synthesis. Chem. Rev. 2013, 113, 3605-3631.

(29) (a) Tavassoli, A.; Duffy, J. E.; Young, D. W. Synthesis of trimethyl $(2 S, 3 R)-$ and $(2 R, 3 R)-\left[2-{ }^{2} \mathrm{H}_{1}\right]$-homocitrates and dimethyl $(2 S, 3 R)$ - and $(2 R, 3 R)-\left[2-{ }^{2} \mathrm{H}_{1}\right]$-homocitrate lactones-an assay for the stereochemical outcome of the reaction catalysed both by homocitrate synthase and by the Nif-V protein. Org. Biomol. Chem. 2006, 4, 569580; (b) Tavassoli, A.; Duffy, J. E. S.; Young, D. W. Synthesis of trimethyl $(2 S, 3 R)-$ and $(2 R, 3 R)-\left[2-{ }^{2} \mathrm{H}_{1}\right]$-homocitrates and the corresponding dimethyl ester lactones-towards elucidating the stereochemistry of the reaction catalysed by homocitrate synthase and by the Nif-V protein. Tetrahedron Lett. 2005, 46, 2093-2096.

(30) Pansare, S. V.; Adsool, V. A. Enantioselective synthesis of (R)-homocitric acid lactone. Tetrahedron Lett. 2007, 48, 7099-7101.

(31) 1,2-Hydride shifts triggered by boron Lewis acids have been explored in 1,1-carboborations: (a) Chen, C.; Voss, T.; Frohlich, R.; Kehr, G.; Erker, G. 1,1-carboboration of 1-alkynes: a conceptual alternative to the hydroboration reaction. Org. Lett. 2011, 13, 62-65; (b) Kehr, G.; Erker, G. 1,1-Carboboration. Chem. Commun. 2012, 48, 1839-1850; (c) Hansmann, M. M.; Melen, R. L.; Rudolph, M.; Rominger, F.; Wadepohl, H.; Stephan, D. W.; Hashmi, A. S. Cyclopropanation/Carboboration Reactions of Enynes with $\mathrm{B}\left(\mathrm{C}_{6} \mathrm{~F}_{5}\right)_{3}$. J. Am. Chem. Soc. 2015, 137, 15469-15477.

(32) Parr, R. G.; Yang, W. Density Functional Theory of Atoms and Molecules; Oxford University Press: New York, 1989. 